\title{
Severe malaria - a case of fatal Plasmodium knowlesi infection with post-mortem findings: a case report
}

\author{
Janet Cox-Singh ${ }^{1,2^{*}+}$, Jessie Hiu ${ }^{3+}$, Sebastian B Lucas $^{4}$, Paul C Divis ${ }^{2}$, Mohammad Zulkarnaen², Patricia Chandran ${ }^{5}$, \\ Kum T Wong ${ }^{5}$, Patricia Adem ${ }^{6}$, Sherif R Zaki ${ }^{6}$, Balbir Singh², Sanjeev Krishna ${ }^{1,2}$
}

\begin{abstract}
Background: Zoonotic malaria caused by Plasmodium knowlesi is an important, but newly recognized, human pathogen. For the first time, post-mortem findings from a fatal case of knowlesi malaria are reported here.

Case presentation: A formerly healthy 40 year-old male became symptomatic 10 days after spending time in the jungle of North Borneo. Four days later, he presented to hospital in a state of collapse and died within two hours. He was hyponatraemic and had elevated blood urea, potassium, lactate dehydrogenase and amino transferase values; he was also thrombocytopenic and eosinophilic. Dengue haemorrhagic shock was suspected and a postmortem examination performed. Investigations for dengue virus were negative. Blood for malaria parasites indicated hyperparasitaemia and single species P. knowlesi infection was confirmed by nested-PCR. Macroscopic pathology of the brain and endocardium showed multiple petechial haemorrhages, the liver and spleen were enlarged and lungs had features consistent with ARDS. Microscopic pathology showed sequestration of pigmented parasitized red blood cells in the vessels of the cerebrum, cerebellum, heart and kidney without evidence of chronic inflammatory reaction in the brain or any other organ examined. Brain sections were negative for intracellular adhesion molecule-1. The spleen and liver had abundant pigment containing macrophages and parasitized red blood cells. The kidney had evidence of acute tubular necrosis and endothelial cells in heart sections were prominent.

Conclusions: The overall picture in this case was one of systemic malaria infection that fit the WHO classification for severe malaria. Post-mortem findings in this case were unexpectedly similar to those that define fatal falciparum malaria, including cerebral pathology. There were important differences including the absence of coma despite petechial haemorrhages and parasite sequestration in the brain. These results suggest that further study of knowlesi malaria will aid the interpretation of, often conflicting, information on malaria pathophysiology in humans.
\end{abstract}

\section{Background}

The underlying pathophysiology of malaria is not well understood despite considerable and prolonged international research effort. This effort is largely driven by the need to reduce the impact of Plasmodium falciparum on human life, particularly in African children [1,2]. Part of the difficulty in studying the pathophysiology of $P$. falciparum malaria is the lack of a permissive animal model and a comparator disease in man. With the

\footnotetext{
* Correspondence: coxsingh@gmail.com; coxsingh@gmail.com † Contributed equally

${ }^{1}$ Division of Cellular and Molecular Medicine, Centre For Infection, St George's University of London, Cranmer Terrace, London SW17 ORE, UK
}

recent discovery of severe malaria, caused by the zoonotic parasite Plasmodium knowlesi in the human population of Southeast Asia [3,4], it is now possible to link findings in primates and humans through this common agent.

In the natural primate hosts (long and pig-tailed macaques), $P$. knowlesi causes asymptomatic low-grade parasitism. In contrast, hyperparasitaemia and death ensue in the well-used Rhesus experimental model [5]. Consequently, there is much information on experimental P. knowlesi malaria, including organ pathology in various animal models [6-8]. Natural P. knowlesi infections of humans were formerly missed because of 
morphological similarity with Plasmodium malariae $[9,10]$. Now clinical descriptions of knowlesi malaria encompass a spectrum of disease ranging from uncomplicated to fatal malaria [3,4].

The pathophysiology of severe knowlesi malaria in humans is undescribed, but nonetheless important for several reasons. First, to provide improved guidelines for the diagnosis, treatment and management of severe knowlesi cases. Secondly, when severe knowlesi infection is compared with severe falciparum malaria, this can help clarify determinants of severe disease. Thirdly, it is possible that we are observing a $P$. knowlesi vertebrate host switch from Southeast Asian macaques to a fullblown emergence into the human population $[11,12]$. Therefore, it is important to understand properly the disease caused by P. knowlesi to assist strategies to reduce health-impacts if human-to-human transmission of this virulent pathogen is established.

The clinical, laboratory and, for the first time, postmortem findings in a fatal case of knowlesi malaria are reported here. The histopathology in various organs is explained within the context of P. knowlesi biology and comparisons with the salient features made with what is known of the pathophysiology of severe falciparum malaria [13-16].

\section{Case presentation}

\section{History and examination}

A forty year-old male was brought to the Queen Elizabeth Hospital, Kota Kinabalu, Sabah $(8.30 \mathrm{am})$ in a state of collapse. He was unable to give a history himself or to stand. On examination his blood pressure was unrecordable and oxygen saturations were recorded as low.

The patient had no past medical history. He had spent two weeks in the jungles of Borneo before leaving for an urban setting. Ten days after leaving the jungle he experienced the onset of fever and body aches. Two days later, he sought treatment at a government outpatient clinic continuing to complain of fever and myalgia. A specific diagnosis was not made and he was able to work although he developed rashes the next day. He remained unwell for the next two days, when he presented in a state of collapse and had developed abdominal pain.

Resuscitation measures were begun and the patient was immediately intubated, given adrenaline/atropine and sodium bicarbonate. On examination and after resuscitation measures his vital signs were: symmetrical air entry into lungs, BP 58/44 mm $\mathrm{Hg}$, pulse rate 40-50 per minute with poor peripheral perfusion and cyanosis. Heart sounds were normal. He had generalized petechiae and his abdomen was tense and distended.

Resuscitation measures continued for one hour, during which time "coffee grounds" were observed in the nasogastric aspirate. The patient became asystolic after one hour and although cardiopulmonary resuscitation was given for a further 20 minutes, there was no response. The patient was pronounced dead two hours after admission.

Dengue haemorrhagic shock was suspected and a post-mortem examination was performed approximately 24 hours later.

\section{Laboratory findings}

Laboratory results are summarized in Table 1 . The patient was not anemic, but was thrombocytopenic and had an eosinophilia. He was also hyponatraemic and had elevated blood urea, potassium, lactate dehydrogenase and amino transferase values. Serum creatinine was not available. A blood sample taken 24 hours post-mortem showed $>10 \%$ of erythrocytes infected with predominantly pigmented parasites (Figure 1a). Heavily pigmented monocytes were also present (Figure 1b). Plasmodium knowlesi, as a single species infection, was confirmed by nested-PCR [9]. Post-mortem dengue serology was negative (Table 1) and dengue, respiratory syncytial virus and enterovirus were not isolated in organ samples.

\section{Post-mortem examination}

External examination showed a well-nourished adult male. The conjunctivae showed tinges of jaundice and the right eye had subconjunctival haemorrhages. There were multiple petechial haemorrhages on the body and venepuncture sites were associated with marked bruising. Coffee ground material was noted in the mouth. Internal examination revealed no tissue oedema or excess fluid in the body cavities.

\section{Macroscopic pathology}

The external surfaces of the cerebrum were dusky. The cut sections showed multiple petechial haemorrhages. The cerebellum also showed petechial haemorrhages externally and on multiple cut sections (Figure 2a and $2 b)$. The brain stem and upper spinal chord were grossly normal. Both lungs were heavy (weighing on the right $720 \mathrm{~g}$ and left $690 \mathrm{~g}$ ) and cut sections were congested

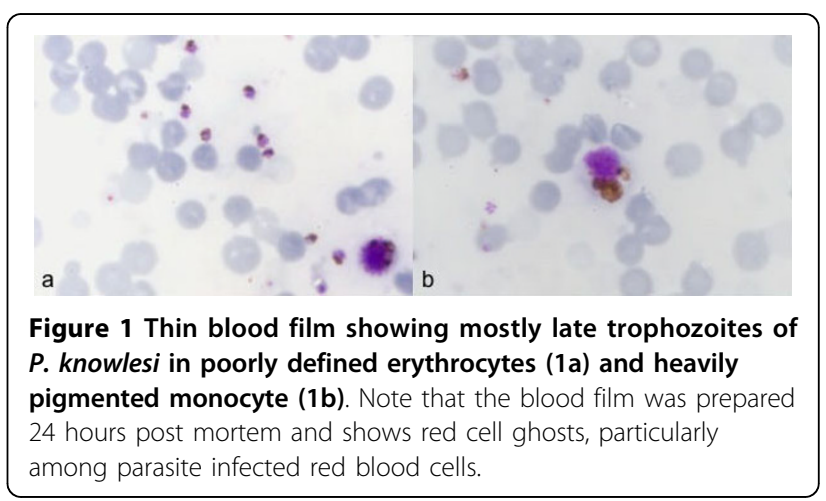


Table 1 Admission laboratory findings

\begin{tabular}{lcc}
\hline Parameter & $\begin{array}{c}\text { Values normal } \\
\text { [range] }\end{array}$ & Values observed \\
\hline Haemoglobin (g/dL) & {$[13 \cdot 5-17 \cdot 5]$} & 12.7 \\
Platelets (/uL) & {$[150,000-450,000]$} & 42,800 \\
Haematocrit (\%) & {$[42-54]$} & 36.7 \\
Total white blood cells (/uL) & {$[4,500-11,000]$} & 10.1 \\
Neutrophils (\%) & & 15.1 \\
Lymphocytes (\%) & & 36.7 \\
Monocytes (\%) & & 12.1 \\
Eosinophils (\%) & & 33.9 \\
Basophils (\%) & {$[4-5]$} & 2.17 \\
Red blood cells (X 10 $/ \mathrm{uL})$ & 4.86 \\
Mean Cell Volume (fL) & {$[80-100]$} & 75.5 \\
Mean Cell Haemoglobin (pg) & {$[29-31]$} & 26.1 \\
Mean Corpuscular Haemoglobin & {$[32-36]$} & 34.6 \\
concentration & & \\
(g/dL) & {$[7.5-11.5]$} & 11.5 \\
Mean Platelet volume (fL) & {$[135-150]$} & 126 \\
Serum sodium (mmol/L) & {$[3.3-5.1]$} & 6.9 \\
Serum potassium (mmol/L) & {$[1.0-8.3]$} & 34.1 \\
Serum urea (mmol/L) & {$[<38]$} & 131 \\
Serum aspartate amino transferase & {$[<170]$} & 156 \\
(U/L) & {$[240-480]$} & 2777 \\
Serum creatine kinase (U/L) & & \\
Serum lactate dehydrogenase (U/L) & \\
\hline
\end{tabular}

and 'beefy' in appearance. Petechial haemorrhages were present on the endocardium with extensive subendocardial haemorrhages involving the left ventricular wall. The haemorrhages were most prominent at the apex of the heart. The liver $(2640 \mathrm{~g})$ and spleen $(340 \mathrm{~g})$ were markedly enlarged. The cut surfaces of the spleen were soft and friable. The gallbladder, pancreas and kidneys were grossly normal.

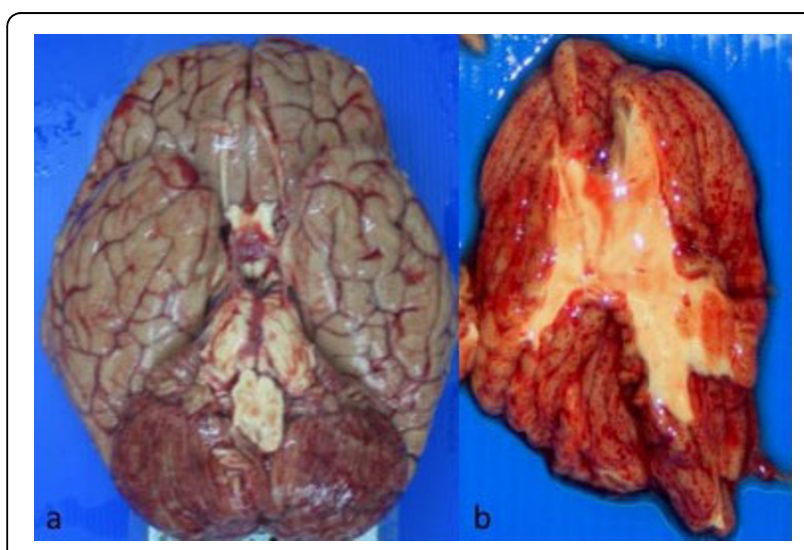

Figure 2 Gross appearance of the brain. The outer surface appears dusky with petechial haemorrhages seen on the outer surface of the cerebellum (2a). Cut section of the cerebellum with multiple petechial haemorrhages seen within the cerebellar grey matter (2b).

\section{Microscopic pathology}

Haematoxylin and eosin stained sections from various organs were available for examination. Parasitized red blood cells (PRBC) were abundant although parasite bodies were obscured by haemozoin (malaria) pigment. Chemical removal of pigment and oil immersion $(\times 1,000)$ magnification revealed trophozoites that were discernibly bigger than those of P. falciparum. Immunohistochemistry stained sections from the brain were Plasmodium anti-aldolase positive (Figure 3 ) and negative for $P$. falciparum- specific staining [17].

Many petechial haemorrhages (up to $600 \mu \mathrm{m}$ diameter) arising from the rupture of the small vessels of the cerebrum and cerebellum were observed (Figures $4 \mathrm{a}$ and $4 \mathrm{~b}$ ) Sequestration of PRBC was evident within small blood vessels (Figures 4c and 4d). Congested larger vessels and areas of haemorrhage showed considerable amounts of malaria pigment (Figures $4 \mathrm{e}$ and $4 \mathrm{f})$. Clumps of platelets or evidence of thrombi in vessels were not seen. There was no evidence of vasculitis or perivascular chronic inflammatory reaction in the brain or any other organ examined (heart, kidney, liver, adrenal gland and spleen). There was no evidence of perivascular or diffuse parenchymal oedema in the brain. Diffuse astrocytosis or microgliosis was not observed, nor was there evidence for acute gliotic reactions about the haemorrhages. There was no aggregation of polymorphs in the vessels, no perivascular inflammation, nor generalized encephalitis. There was no diffuse thrombotic microangiopathy, but within one haemorrhage there was probably some fibrin at the site of the vessel. Immunohistochemistry of sections from the brain was negative for CD54 (which stains intercellular adhesion molecule-1, ICAM-1).

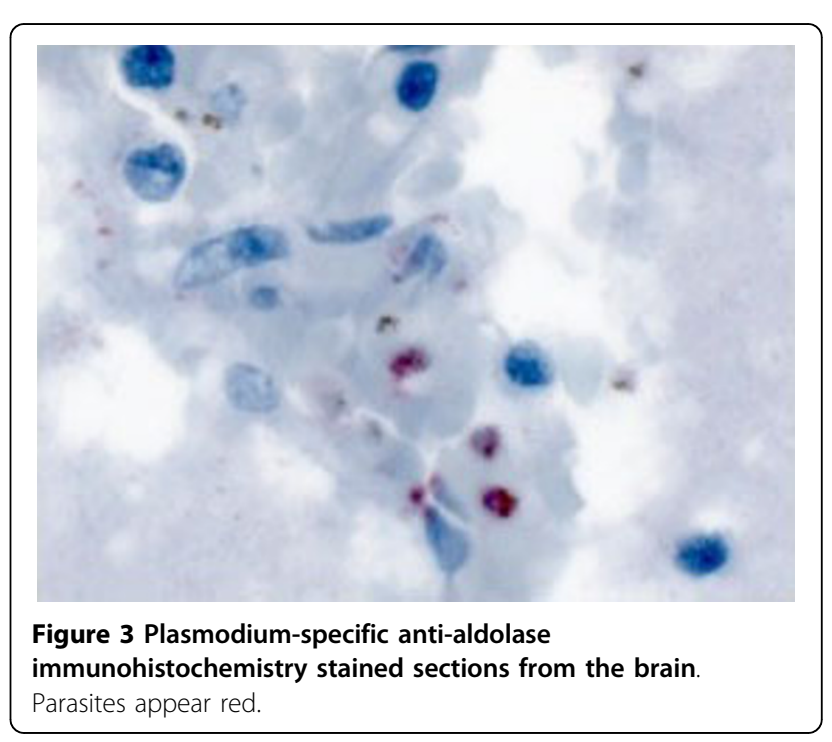




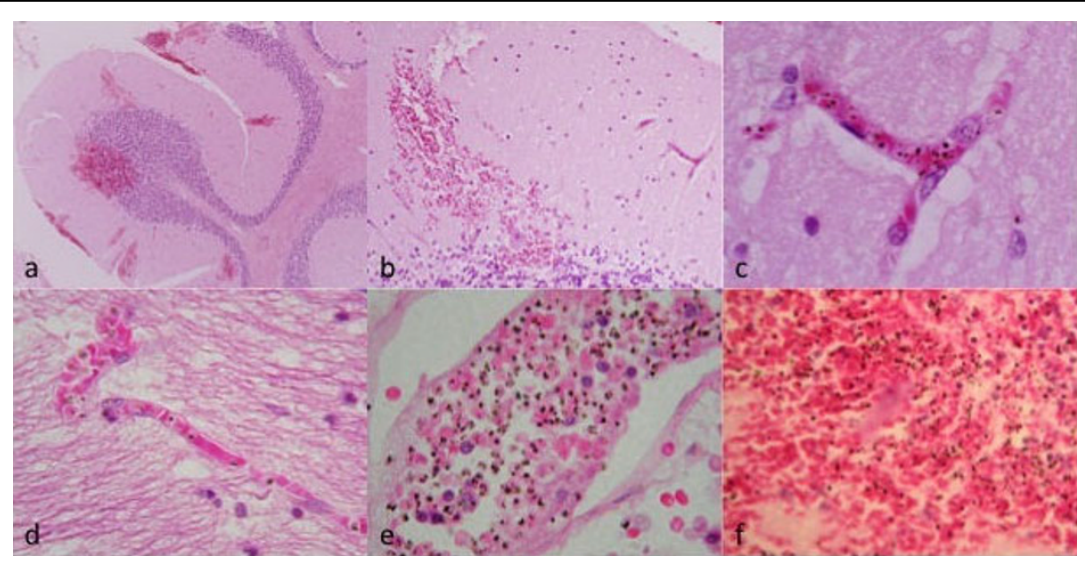

Figure 4 Haematoxylin and eosin stained sections of the cerebellum (a, b, c, e, f) and cerebrum (d). Low power view showing haemorrhages in the grey and white matter $\times 20$ (4a). Haemorrhage in the cerebellar molecular layer $\times 40$ (4b). $4 \mathrm{c} \times 400$ and $4 \mathrm{~d}$ both $\times 200$ show capillaries with sequestered parasitized red blood cells. There was no perivascular inflammation nor intravascular thrombosis. Venule with parasitized red blood cells $\times 200$ (4e) and haemorrhage showing mixture of parasitized and non-parasitized red blood cells $\times 400$ (4f).

Although sections from the spleen showed some autolysis, expansion of the red pulp and atrophy of the white pulp was noted. Germinal centers were not observed. Abundant pigment-containing macrophages and some haemophaghocytosis was evident in the red pulp and parasitized red cells were plentiful (Figure 5a). There was no necrosis or fibrin deposition in the spleen.

There were many PRBC's in the liver sinusoids with haemozoin pigment in Kupffer cells and evidence of haemophagocytosis. The portal tracts and sinusoids had moderate chronic lymphoplasmacytic inflammation. Overall the liver was non-cirrhotic but with severe macrovesicular steatosis. No cholestasis, regional necrosis or thrombotic microangiopathy was observed (Figure 5b).

The renal cortex showed dilated and congested blood vessels. Many PRBC were observed within glomerular capillaries with pigment deposition in the mesangium. There was no evidence of thrombotic microangiopathy (disseminated intravascular coagulation, DIC). The tubules showed acute tubular necrosis and regeneration.
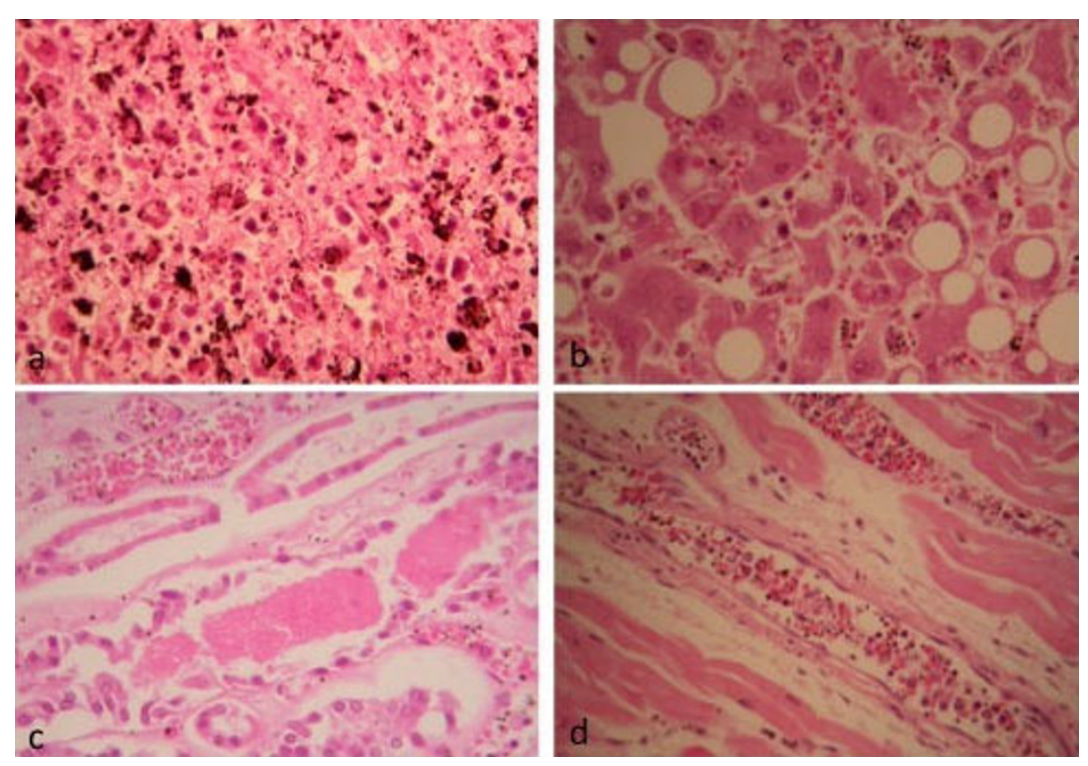

Figure 5 Haematoxylin and eosin stained extra cerebral tissues. (5a) spleen $\times 400$ showing red pulp macrophages containing much haemozoin pigment as well as phagocytozed red blood cells. (5b) liver $\times 400$ showing macrovesicular steatosis of hepatocytes without parenchymal inflammation. The sinusoids have abundant parasitized red blood cells as well as Kupffer cells containing haemozoin. (5c) kidney $x$ 200 showing acute tubular necrosis and intratubular casts. Intravascular parasitized red blood cells also visible. The myofibres of the left ventricle of the heart are normal $(5 \mathrm{~d} \times 200)$. Small veins and capillaries contain abundant parasitized red blood cells and endothelial cells are prominent. 
There were a small number of eosinophilic intra-tubular casts (Figure 5c).

Sequestration of PRBC's was evident in the small vessels of the heart (Figure 5d). Endothelial cells were prominent as sometimes observed in patients with sepsis whose cells are responding to generalized stimuli [18]. There was no evidence of myocarditis and the heart muscle fibers appeared normal. There was focal petechial haemorrhage in the subendocardium, which may relate to resuscitation, or be secondary to malaria.

The adrenal gland appeared active with eosinophilic cytoplasm in the fasciculata layer with no evidence of PRBC sequestration or of parenchymal haemorrhage. Samples of lung, intestine or bone marrow were not available for histopathology examination.

The overall picture was one of systemic malaria infection with multi-organ damage, particularly in the brain where there was much vascular rupture and petechial haemorrhaging.

\section{Conclusions}

Fatal human knowlesi malaria has hitherto not been reported at post-mortem, so this report may increase our understanding of severe and fatal malaria whatever species cause these syndromes. Interestingly, vivax malaria is also becoming recognized as causing severe and sometimes fatal infection in a significant proportion of individuals, suggesting re-evaluation of the dogma that falciparum infection may be the only important cause of fatal disease [19-21].

The WHO classification for severe falciparum malaria would have included this individual because he had several qualifying features including hyperparasitaemia ( $10 \%$ infected erythrocytes), renal impairment, jaundice and ARDS, although coma was not prominent in the history [3,4,22]. Commonly, dengue haemorrhagic fever can cause some of these signs, but was excluded by investigations. Co-infection of knowlesi with falciparum was also excluded by specific PCR and immunohistochemical examination.

The beefy appearance of lung tissue in this case is consistent with respiratory distress syndrome, but could not be confirmed histologically. Changes in the kidney of some recovering areas of acute tubular injury are consistent with the observation of renal impairment reported in other severe cases of knowlesi malaria[3] and an underlying process of acute tubular necrosis related to systemic shock. There was disorganized white pulp in spleen perhaps as part of a wider stress response [18].

Despite the absence of antecedent established coma, cerebral pathology in this case is very similar to that observed in fatal falciparum infections, confirming that it was important to exclude this co-infection. Although there was obvious accumulation/sequestration of infected erythrocytes in capillaries and venules, there were also some differences between these appearances and those seen with fatal falciparum infections. For example, there was no platelet clumping, no notable thrombi, and uninfected erythrocytes were also interspersed with infected cells. Neither was up-regulation of ICAM-1 expression detected in endothelial cells, suggesting that the mechanism of sequestration/accumulation of infected erythrocytes in knowlesi infections needs further investigation. In falciparum cerebral malaria, display of ICAM-1 by up regulated endothelial cells mediates adhesion to parasitized red cells [19].

Hyperparasitaemia is a marker of severe falciparum malaria. It is also apparent in severe knowlesi infections [3], but is less commonly observed with severe vivax malaria. The $24 \mathrm{hr}$ replicative cycle of asexual knowlesi may contribute to the rapidity with which hyperparasitaemia and clinical complications ensue. This shorter cycle compared with falciparum and vivax infections may overcome the reduced multiplicative capacity associated with the fewer merozoites generated by $P$. knowlesi (up to 16 per mature schizont) compared with $P$. falciparum (up to 36). Although up to 24 merozoites per schizont have been observed in Plasmodium vivax, parasitaemia is restricted to reticulocytes by limitation of invasion pathways in this species, rather than merozoite number.

Hyperparasitaemia in falciparum malaria is often explained by protection of late stage parasites from the filtering action of the spleen. Unlike P. falciparum infections, all asexual developmental stages are seen in the peripheral circulation of knowlesi-infected patients [10]. Hyperparasitaemia in knowlesi malaria may not be modulated by splenic clearance in a similar manner as suggested for other non-sequestering human infections.

As with many fatal cases of falciparum malaria, malaria pigment was evident in blood films and was present in circulating leucocytes $(\sim 40 \%)$, tissue sections and organ specific macrophages. Reticuloendothelial changes in both liver and spleen were associated with pigment, accumulation of red cells and laden macrophages, and some inflammation in liver portal tracts was observed. Circulating pigment has been variably implicated as an indicator of poor prognosis for falciparum malaria [23-25] and there is evidence to support pigmentinduced immuno-suppression, particularly of pigmentladen macrophages and monocytes [26-28]. It may be that the associations between parasitaemia, pigmentaemia and disease severity are more quantifiable in knowlesi compared with falciparum infections, where pigmented parasites are sequestered from peripheral blood samples and, therefore, unreliably quantifiable. In vivax malaria, pigment in parasites often appears more 
dispersed and it is rarely reported as a correlate of disease [29].

Among the malaria parasites of humans, cytoadherence is purportedly unique to $P$. falciparum, resulting in sequestration of all but early trophozoite stages in falciparum malaria. Cytoadherence is often implicated in malaria pathology and is mediated by the expression of variable var gene products (of the PfEMP-1 family) at the surface of infected host red blood cells with concomitant expression of post-capillary endothelial cell receptors [15,30-32]. Although not easily quantifiable, partial sequestration was observed in this fatal case of knowlesi malaria as evidenced by an abundance of large pigment bearing parasites on the blood film obtained post-mortem and as accumulations in the microvasculature. We hypothesize that partial sequestration may be due to $P$. knowlesi infected cell agglutination mediated by variant surface antigens of $P$. knowlesi SICA var genes (orthologues of the PfEMP-1 family) [33,34]. Importantly, in this fatal case of $P$. knowlesi, up-regulation of ICAM-1 was not detected, nor was there evidence for cytoadherence as parasitized cells were not marginalized and were interspersed with uninfected erythrocytes in smaller vessels.

Cerebral malaria and severe acute anaemia are often peculiar to falciparum infection while organ, respiratory and metabolic dysfunction are common with severe knowlesi, vivax and other forms of severe falciparum infection [3,4,19,35-40]. Although late stages of parasites may be visible in the blood in falciparum infections, they are rare and associated with a poor prognosis. Testing the relative contribution of virulence factors to the development of severe malaria including, cytoadherence, hyperparasitaemia, cerebral malaria, organ failure, metabolic and respiratory dysfunction and anaemia was previously difficult without comparative information from severe malaria caused by another species [16,41-44]. Severe and fatal cases of knowlesi malaria will add much needed perspective to what is known of malaria pathophysiology.

The need to develop knowlesi-specific diagnosis, treatment and management guidelines is urgent. A recent prospective clinical study in Sarawak Malaysian Borneo revealed that approximately 1:10 patients infected with P. knowlesi present with or develop severe symptoms and $1-2 \%$ of cases are fatal [4]. Complications in survivors included ARDS, liver or renal dysfunction, hypotension with or without parasitaemia $>100,000 /$ uL. Complications in all fatal knowlesi cases had either clinical or laboratory evidence of abdominal pain, combined hepatorenal dysfunction and hyperparasitaemia $[3,4]$. There is a prospect that $P$. knowlesi may emerge as a human pathogen beyond its current zoonotic manifestations $[11,12]$, specific surveillance, control and clinical guidelines are necessary to contain potential larger outbreaks.

\section{Consent}

Approval to use this case for educational purposes was obtained from the Deputy Director for Health, Sabah State Department of Health, Ministry of Health, Malaysia.

\section{Acknowledgements}

We acknowledge the contributions of Mr Fread Anderios, Microbiologist, Kota Kinabalu Public Health Laboratory, Malaysian Ministry of Health, Drs Ganesan Durairajah and Timothy William Queen Elizabeth Hospital, Sabah. JCS and SK are funded by the Medical Research Council (UK) Grant Number RAA 0033, this work was funded in part by the Wellcome Trust (BS and JCS Grant Number 078538/Z/05/Z).

\section{Author details}

${ }^{1}$ Division of Cellular and Molecular Medicine, Centre For Infection, St George's University of London, Cranmer Terrace, London SW17 ORE, UK. ${ }^{2}$ Malaria Research Centre, University Malaysia Sarawak, Kuching, Sarawak, Malaysia. ${ }^{3}$ Department of Forensic, Queen Elizabeth Hospital, Kota Kinabalu, Sabah, Malaysia. ${ }^{4}$ Department of Histopathology, KCL School of Medicine, St Thomas' Hospital, London, UK. ${ }^{5}$ Department of Pathology, Faculty of Medicine, University of Malaya, Kuala Lumpur, Malaysia. Infectious Diseases Pathology Branch, Centers for Disease Control and Prevention, Atlanta, Georgia, USA.

\section{Authors' contributions}

JCS collected and collated case information and details and obtained consent. $\mathrm{JH}$ performed the post mortem, provided gross pathology images and provided the autopsy report. PCD, ZSR, PC and AP performed PCR, Immunohistochemistry and sample processing. SK, SBL, ANZ and WKT prepared and reviewed the clinical, histopathology and pathology reports. $\mathrm{SBL}$ and BS provided descriptions and information for the manuscript. JCS and SK wrote the manuscript. All authors have read and approved the final manuscript.

\section{Competing interests}

The authors declare that they have no competing interests.

\section{Received: 6 November 2009}

Accepted: 11 January 2010 Published: 11 January 2010

\section{References}

1. Snow RW, Guerra CA, Mutheu JJ, Hay SI: International funding for malaria control in relation to populations at risk of stable Plasmodium falciparum transmission. Plos Med 2008, 5:e142.

2. World Health Organization, World Malaria Report. 2008.

3. Cox-Singh J, Davis TM, Lee KS, Shamsul SS, Matusop A, Ratnam S, Rahman HA, Conway DJ, Singh B: Plasmodium knowlesi malaria in humans is widely distributed and potentially life threatening. Clin Infect Dis 2008, 46:165-171.

4. Daneshvar C, Davis C, Cox-Singh J, Rafa'ee M, Zakaria S, Divis P, Singh B: Clinical and laboratory features of human Plasmodium falciparum infections. Clin Infect Dis 2009, 49:852-860.

5. Coatney GR, Collins WE, Warren M, Contacos PG: The primate malarias Bethesda, MD: U.S. Department of Health, Education and Welfare, National Institutes of Health 1971

6. Langhorne J, Cohen S: Plasmodium knowlesi in the marmoset (Callithrix jacchus). Parasitology 1979, 78:67-76.

7. Ozwara H, Langermans JA, Maamun J, Farah IO, Yole DS, Mwenda JM, Weiler H, Thomas AW: Experimental infection of the olive baboon (Papio anubis) with Plasmodium knowlesi: severe disease accompanied by cerebral involvement. Am J Trop Med Hyg 2003, 69:188-194.

8. Miller LH, Fremount HN, Luse SA: Deep vascular schizogony of Plasmodium knowlesi in Macaca mulatta. Distribution in organs and 
ultrastructure of parasitized red cells. Am J Trop Med Hyg 1971, 20:816 824.

9. Singh B, Kim Sung L, Matusop A, Radhakrishnan A, Shamsul SS, Cox-Singh J, Thomas A, Conway DJ: A large focus of naturally acquired Plasmodium knowlesi infections in human beings. Lancet 2004, 363(9414):1017-1024.

10. Lee KS, Cox-Singh J, Singh B: Morphological features and differential counts of Plasmodium knowlesi parasites in naturally acquired human infections. Malar J 2009, 8:73.

11. Cox-Singh J, Singh B: Knowlesi malaria: newly emergent and of public health importance?. Trends Parasitol 2008, 24:406-410.

12. McCutchan FE: Is monkey malaria from Borneo an emerging human disease?. Future Microbiol 2008, 3:115-118.

13. Newton CR, Krishna S: Severe falciparum malaria in children: current understanding of pathophysiology and supportive treatment. Pharmacol Ther 1998, 79:1-53.

14. Taylor TE, Fu WJ, Carr RA, Whitten RO, Mueller JS, Fosiko NG, Lewallen S, Liomba NG, Molyneux ME: Differentiating the pathologies of cerebral malaria by postmortem parasite counts. Nat Med 2004, 10:143-145.

15. Turner GD, Morrison H, Jones M, Davis TM, Looareesuwan S, Buley ID, Gatter KC, Newbold Cl, Pukritayakamee S, Nagachinta B, White NJ, Berendt AR: An immunohistochemical study of the pathology of fatal malaria. Evidence for widespread endothelial activation and a potential role for intercellular adhesion molecule-1 in cerebral sequestration. Am J Pathol 1994, 145:1057-1069.

16. White N: Malaria pathophysiology. Malaria: Parasite Biology, Pathogenesis and Protection Washington DC: ASM PressSherman IW 1998, 371-385.

17. Genrich GL, Guarner J, Paddock CD, Shieh WJ, Greer PW, Barnwell JW, Zaki SR: Fatal malaria infection in travelers: novel immunohistochemical assays for the detection of Plasmodium falciparum in tissues and implications for pathogenesis. Am J Trop Med Hyg 2007, 76:251-259.

18. Lucas S: The autopsy pathology of sepsis-related death. Current Diagnostic Pathology 2007, 13:375-388.

19. Anstey NM, Handojo T, Pain MC, Kenangalem E, Tjitra E, Price RN, Maguire GP: Lung injury in vivax malaria: pathophysiological evidence for pulmonary vascular sequestration and posttreatment alveolarcapillary inflammation. J Inf Dis 2007, 195:589-596.

20. Beg MA, Khan R, Baig SM, Gulzar Z, Hussain R, Smego RA Jr: Cerebral involvement in benign tertian malaria. Am J Trop Med Hyg 2002 67(3):230-232

21. Genton B, D'Acremont V, Rare L, Baea K, Reeder JC, Alpers MP, Muller I: Plasmodium vivax and mixed infections are associated with severe malaria in children: a prospective cohort study from Papua New Guinea. Plos Med 2008, 5:e127.

22. WHO: Severe falciparum malaria. World Health Organizsation, Communicable Diseases Cluster. Trans R Soc Trop Med and Hyg 2000, 94(Suppl 1):S1-90.

23. Kremsner PG, Valim C, Missinou MA, Olola C, Krishna S, Issifou S, Kombila M, Bwanaisa L, Mithwani S, Newton CR, Agbenyega T, Pinder M, Bojang K, Wypij D, Taylor T: Prognostic value of circulating pigmented cells in african African children with malaria. J Inf Dis 2009, 199:142-150

24. Lyke KE, Diallo DA, Dicko A, Kone A, Coulibaly D, Guindo A, Cissoko Y, Sangare L, Coulibaly S, Dakouo B, Taylor T, Doumbo OK, Plowe C: Association of intraleukocytic Plasmodium falciparum malaria pigment with disease severity, clinical manifestations, and prognosis in severe malaria. Am J Trop Med Hyg 2003, 69:253-259.

25. Nguyen PH, Day N, Pram TD, Ferguson DJ, White NJ: Intraleucocytic malaria pigment and prognosis in severe malaria. Trans R Soc Trop Med Hyg 1995, 89:200-204.

26. Awandare GA, Ouma Y, Ouma C, Were T, Otieno R, Keller CC, Davenport GC, Hittner JB, Vulule J, Ferrell R, Ong'echa JM, Perkins D: Role of monocyte-acquired hemozoin in suppression of macrophage migration inhibitory factor in children with severe malarial anemia. Infect Immun 2007, 75:201-210

27. Carney CK, Schrimpe AC, Halfpenny K, Harry RS, Miller CM, Broncel M, Sewell SL, Schaff JE, Deol R, Carter MD, Wright DW: The basis of the immunomodulatory activity of malaria pigment (hemozoin). J Biol Inorg Chem 2006, 11:917-929.

28. Deshpande P, Shastry P: Modulation of cytokine profiles by malaria pigment-hemozoin: role of IL-10 in suppression of proliferative responses of mitogen stimulated human PBMC. Cytokine 2004, 28:205 213
29. McGready R, Davison BB, Stepniewska K, Cho T, Shee H, Brockman A, Udomsangpetch R, Looareesuwan S, White NJ, Meshnick SR, Nosten F: The effects of Plasmodium falciparum and $P$. vivax infections on placental histopathology in an area of low malaria transmission. Am J Trop Med Hyg 2004, 70:398-407.

30. Su XZ, Heatwole VM, Wertheimer SP, Guinet F, Herrfeldt JA, Peterson DS, Ravetch JA, Wellems TE: The large diverse gene family var encodes proteins involved in cytoadherence and antigenic variation of Plasmodium falciparum-infected erythrocytes. Cell 1995, 82:89-100.

31. Flick K, Chen Q: var genes, PfEMP1 and the human host. Mol Biochem Parasitol 2004, 134:3-9.

32. Ockenhouse CF, Tegoshi T, Maeno Y, Benjamin C, Ho M, Kan KE, Thway Y Win K, Aikawa M, Lobb RR: Human vascular endothelial cell adhesion receptors for Plasmodium falciparum-infected erythrocytes: roles for endothelial leukocyte adhesion molecule 1 and vascular cell adhesion molecule 1. J Exp Med 1992, 176:1183-1189.

33. Pain A, Bohme U, Berry AE, Mungall K, Finn RD, Jackson AP, Mourier T, Mistry J, Pasini EM, Aslett MA, Balasubrammaniam S, Borgwardt K, Brooks K, Carret C, Carver TJ, Cherevach I, Chillingworth T, Clark TG, Galinski MR, Hall N, Harper D, Harris D, Hauser H, Ivens A, Janssen CS, Keane T, Larke N, Lapp S, Marti M, Moule S, Meyer IM, Ormond D, Peters N, Sanders M, Sanders S, Sargeant TJ, Simmonds M, Smith F, Squares R, Thurston S, Tivey AR, Walker D, White B, Zuiderwijk E, Churcher C, Quail MA, Cowman AF, Turner CMR, Rajandream MA, Kocken CHM, Thomas AW, Newbold Cl, Barrell BG, Berriman M: The genome of the simian and human malaria parasite Plasmodium knowlesi. Nature 2008, 455:799-803.

34. Barnwell JW, Howard RJ, Miller LH: Altered expression of Plasmodium knowlesi variant antigen on the erythrocyte membrane in splenectomized rhesus monkeys. J Immunol 1982, 128:224-226.

35. Price L, Planche T, Rayner C, Krishna S: Acute respiratory distress syndrome in Plasmodium vivax malaria: case report and review of the literature. Trans R Soc Trop Med Hyg 2007, 101:655-659.

36. Coltel N, Combes V, Hunt NH, Grau GE: Cerebral malaria - a neurovascular pathology with many riddles still to be solved. Curr Neurovasc Res 2004, 1:91-110.

37. Deitsch KW, Hviid L: Variant surface antigens, virulence genes and the pathogenesis of malaria. Trends Parasitol 2004, 20:562-566.

38. Idro R, Jenkins NE, Newton CR: Pathogenesis, clinical features, and neurological outcome of cerebral malaria. Lancet Neurol 2005, 4:827-840.

39. Sun G, Chang WL, Li J, Berney SM, Kimpel D, Heyde van der HC: Inhibition of platelet adherence to brain microvasculature protects against severe Plasmodium berghei malaria. Infect Immun 2003, 71:6553-6561.

40. Taoufiq Z, Gay F, Balvanyos J, Ciceron L, Tefit M, Lechat P, Mazier D: Rho kinase inhibition in severe malaria: thwarting parasite-induced collateral damage to endothelia. J Inf Dis 2008, 197:1062-1073.

41. Beeson JG, Brown GV: Pathogenesis of Plasmodium falciparum malaria: the roles of parasite adhesion and antigenic variation. Cell Mol Life Sci 2002, 59:258-271.

42. Jensen AT, Magistrado P, Sharp S, Joergensen L, Lavstsen T, Chiucchiuini A, Salanti A, Vestergaard LS, Lusingu JP, Hermsen R, Sauerwein R, Chritensen J, Nielsen MA, Hviid I, Sutherland C, Staalsoe T, Theander TG: Plasmodium falciparum associated with severe childhood malaria preferentially expresses PfEMP1 encoded by group A var genes. J Exp Med 2004, 199:1179-1190

43. Newton CR, Taylor TE, Whitten RO: Pathophysiology of fatal falciparum malaria in African children. Am J Trop Med Hyg 1998, 58:673-683.

44. Clark IA, Alleva LM: Is human malarial coma caused, or merely deepened, by sequestration?. Trends Parasitol 2009, 25:314-318.

doi:10.1186/1475-2875-9-10

Cite this article as: Cox-Singh et al: Severe malaria - a case of fatal Plasmodium knowlesi infection with post-mortem findings: a case report. Malaria Journal 2010 9:10. 